\title{
A CRÍTICA DE CHARLES TAYLOR AO NATURALISMO NA CIÊNCIA POLÍTICA
}

\author{
Tiago Losso
}

\begin{abstract}
RESUMO
Os mais recentes esforços de revitalização do enfoque interpretativo na Ciência Politica têm sua gênese na década de 1960, quando vários autores passaram a advogar a centralidade do estudo dos significados lingüístico e hermenêutico dos fenômenos politicos. Dentre tais autores, destaca-se o filósofo e politólogo Charles Taylor, cujos textos dos anos 1960 e 1970 desferem críticas contundentes ao naturalismo subjacente ao mainstream da Ciência Política da época. Meu objetivo é explorar a crítica de Taylor ao naturalismo, pensadas no contexto de uma proposta de abordagem interpretativa para a Ciência Política. Primeiramente, contextualizarei as contribuições de Taylor no âmbito mais amplo do interpretive turn nas Ciências Sociais. Em seguida, sumarizarei as reservas que Quentin Skinner e Clifford Geertz apresentam à crítica de Taylor.
\end{abstract}

PALAVRAS-CHAVE: Ciência Politica; naturalismo; interpretativismo.

\section{INTRODUÇÃO}

As Ciências Sociais ${ }^{1}$ têm, em formulações interpretativistas, pontos fundamentais de sua constituição como campo de saber, sendo Dilthey e Weber as referências óbvias. Os autores responsáveis por essas formulações tiveram de lidar com uma torrente de críticas dirigidas aos seus pressupostos interpretativos, e portanto pouco confiáveis, por praticantes de outras modalidades de investigação do mundo social, marcadamente aqueles que optaram por critérios naturalistas e comportamentais para buscar a verdade sobre o mundo social, sendo a Ciência Política comportamentalista (behaviorist) e empirista norteamericana de meados de século XX um caso exemplar.

Mesmo que as questões relativas à interpretação sejam constantes desde o surgimento das Ciências Sociais, em meados do século passado, uma série de acadêmicos de diversas vinculações disciplinares passou a advogar novos usos e significados para a idéia de interpretação (RABINOW \&

\footnotetext{
1 Assumo as Ciências Sociais como o conjunto de cinco disciplinas (História, Sociologia, Economia, Antropologia e Ciência Política) que se institucionalizaram nas universidades européias e norte-americanas entre meados do século XIX e primeiro terço do século XX.
}

SULLIVAN, 1979). Além de um método para a compreensão do mundo ou da ação social, foi sugerido que a interpretação é definidora mesmo do mundo que pretende ser escrutinado, assumindo, portanto, caráter ontológico. Em algumas formulações, a vida e o mundo social seriam ambos interpretações, já que imersos em linguagem.

Como uma grande onda dessa tensão entre os dois estilos de análise, um conjunto heterogêneo de cientistas sociais passou então a elaborar justificativas metodológicas e epistemológicas para essa modalidade de análise, além de rebater as acusações de seus oponentes - geralmente com contribuições contundentes que pretendiam desacreditar suas capacidades explicativas. Suas considerações constituem um debate polifônico e multifacetado, que abriga diversas posturas frente às questões com que se depara o analista social. Uma noção geral, que orienta o conjunto dessas considerações, é que a ação social seria sempre significativa e a tarefa do cientista social seria a compreensão do que acontece por meio da agência humana ${ }^{2}$.

\footnotetext{
2 Vale mencionar que nas formulações de Max Weber é patente a insistência de que, nas Ciências Sociais, as explicações causais apóiam se em compreensões interpretativas (Verstehen). Cf. Bevir e Kedar (2008, p. 505).
} 
O principal interesse do presente ensaio é iniciar um mapeamento do debate sobre interpretação no âmbito das Ciências Sociais, com especial atenção ao interpretive turn da década de 1960, movimento que reposicionou as questões relativas à interpretação no âmbito das Ciências Sociais. De sugestão marginalizada por diversas correntes de investigação, o interpretativismo passou ao centro das preocupações de diversos estudiosos no período referido. Pretendo acompanhar o movimento que acabou promovendo o revigoramento de uma tradição das ciências humanas, que havia sido negligenciada ao longo de toda a primeira metade do século XX pelos defensores de abordagens naturalistas para a análise do mundo social.

Inicio o texto expondo resumidamente os contornos gerais do movimento de revigoramento das questões interpretativas na seção "O interpretativismo nas Ciências Sociais", delineando o movimento convencionalmente nomeado de interpretive turn. Em seguida, em "Interpretação, naturalismo e antinaturalismo na Ciência Política", abordo os desdobramentos do interpretive turn no âmbito da Ciência Política, dedicando especial atenção a dois escritos de Charles Taylor, estudioso que desferiu críticas contundentes não só aos estilos naturalistas de teorização sobre a política, mas aos fundamentos de uma visão naturalista dos significados do mundo, tanto o natural quanto o social. Para efeito de contraste, sublinharei as semelhanças e contrastes entre as posições de Taylor e as do antropólogo Clifford Geertz. O cotejamento entre dois autores que estabeleceram argumentos poderosos no debate interpretativista pode, simultaneamente, permitir a compreensão do interpretativismo como um fenômeno que possui um contexto explicativo particularmente constituído pelo conjunto das Ciências Sociais, indicando as aproximações e discordâncias que caracterizam um percurso intelectual polifônico.

Em uma breve conclusão, pretendo apontar para a necessidade da procura por justificativas de um estudo compreensivo e interpretativo da ação social, com especial atenção às possibilidades de constituição de uma Ciência Política interpretativa.

\section{O INTERPRETATIVISMO NAS CIÊNCIAS SOCIAIS}

As questões ligadas à interpretação estão enraizadas nas Ciências Sociais. Durante o processo que levou a sua institucionalização nas uni- versidades, as Ciências Sociais contaram com o tratamento dispensado ao tema por autores como Wilhelm Dilthey e Max Weber (TAYLOR, 1985a; GIBBONS, 2006; BEVIR \& KEDAR, 2008). Já no momento de constituição do campo das Ciências Sociais, advogou-se uma perspectiva de análise que buscasse compreender a ação social, distinguindo o procedimento adequado para tal empreitada daquele preconizado pelas ciências naturais. Tanto Dilthey quanto Weber dedicaram especial atenção para a dimensão auto-referenciada do mundo social, tornando a análise social um contato com os significados que orientam a ação social (GIBBONS, 2006).

A postura interpretativista foi tenazmente criticada desde suas primeiras formulações, e a primeira metade do século XX constituiu-se em um ambiente intelectualmente propício ao desenvolvimento de estilos naturalistas de análise social, os quais assumem os pressupostos epistemológicos e metodológicos das ciências naturais como um padrão a ser seguido ao proceder-se ao estudo do mundo social. Alcançar os pressupostos científicos significaria alcançar a maturidade (RABINOW \& SULLIVAN, 1979). A Ciência Política norte-americana é um caso emblemático da aplicação de uma abordagem naturalista às Ciências Sociais.

O desenvolvimento da Ciência Política no período posterior à II Guerra Mundial foi profundamente marcado pelo incremento do sistema universitário norte-americano, tornando os cientistas políticos nos principais artífices de um estilo de reflexão sobre os fenômenos políticos marcadamente interessados na análise do comportamento político; análise esta que privilegiaria a utilização de métodos empiristas, conscientemente rejeitando sua relação com a filosofia política (FERES JR., 2000), um movimento que guarda semelhança com a expulsão da filosofia do âmbito da nascente idéia de ciência, no início da modernidade (COMISSÃO GULBENKIAN, 1996). Advogou-se, já no século XX, uma agenda construída sob bases estritamente empíricas e destituída de valoração. Seguindo-se esses critérios básicos, obter-se-ia a verdade sobre a política (FERES JR., 2000; GIBBONS, 2006).

Enquanto o comportamentalismo (behaviorism) assenhoreava-se dos departamentos universitários, periódicos e associações acadêmicas norte-americanas, fizeram-se críticas aos pressupos- 
tos científicos (no sentido naturalista e/ou empirista) da análise social. Esses críticos, com diversas vinculações disciplinares, protagonizaram um movimento (não planejado como atividade coletiva) de questionamento das bases sobre as quais eram alicerçadas as análises cientificistas do mundo social, constituindo um fenômeno nomeado posteriormente como virada interpretativa (RABINOW \& SULLIVAN, 1979; GIBBONS, 2006).

Tomo as Ciências Sociais como um contexto adequado e necessário para a compreensão do interpretive turn, mesmo que o movimento esteja articulado às ciências humanas. $\mathrm{O}$ autor-chave para identificar essa articulação (tanto do interpretive turn em relação às ciências humanas, quanto entre os autores no seio do fenômeno) é Ludwig Wittgenstein, com Investigações filosóficas. A leitura do filósofo é apontada como fundamental pelos protagonistas da virada aqui considerada. Clifford Geertz cita-o de maneira reverente em sua primeira reflexão de cunho teórico (GEERTZ, 1989 , p. 23) e assume mais tarde simpatizar com a idéia de encará-lo como seu "mestre" (GEERTZ, 2001c, p. 9). O impacto causado pelo "último Wittgenstein" pode ser acompanhado na seguinte passagem: "A principal figura a possibilitar essa mudança \{do olhar filosófico em direção as pequenos detalhes da vida vivida $\}$, se não sua causadora, foi, de novo na minha opinião, esse rebelde póstumo e esclarecedor que foi o 'último Wittgenstein'. O aparecimento em 1953, dois anos após sua morte, das Investigações filosóficas, com a transformação do que não passava de conversas de Oxbridge em um texto com poder gerador aparentemente infinito, teve um enorme impacto no que eu pretendia e sentia esperança de realizar, da mesma forma que o fluxo de 'Observações', 'Momentos', 'Apontamentos' e 'Lembretes' que se seguiram ao Nachlass [alívio] nas décadas subseqüentes. Nisso eu não estava sozinho entre os que trabalhavam em ciências humanas e tentavam encontrar a saída de suas garrafas fechadas" (idem, p. 9; grifos e colchetes no original).

A citação é esclarecedora, tanto sobre a importância intelectual de Investigações filosóficas, quanto acerca da existência de uma comunidade acadêmica às voltas com as mesmas questões epistemológicas, que se desdobrariam em questões teóricas e metodológicas. Essa comunidade pode ser vista em funcionamento na Escola de Ciências Sociais do Instituto de Estudos Avançados de Princeton, em que circularam, entre ou- tros, Charles Taylor, Thomas Kuhn e Quentin Skinner, com a lembrança óbvia do papel proeminente e constante de Clifford Geertz (idem, p. 11; SKINNER, 2000, p. 317).

A filosofia analítica (ou pós-analítica), partindo dos trabalhos de Ludwig Wittgenstein, Alasdair MacIntyre e de Charles Taylor, foi fundamental para o desenvolvimento de uma postura antinaturalista no âmbito das ciências humanas e, de maneira específica, entre as Ciências Sociais (BEVIR \& KEDAR, 2008, p. 505). Entre os diversos resultados dessa influência digna de nota temos uma inflexão no campo da história intelectual, protagonizada por acadêmicos vinculados à Universidade de Cambridge. Uma breve sumarização das pretensões e sugestões desses autores será aqui útil em dois sentidos: permitirá contextualizar a perspectiva interpretativista nas Ciências Sociais e fornecerá um amparo teórico à história intelectual aqui apresentada.

Uma postura interpretativista exemplar pode ser acompanhada nas formulações da Escola de Cambridge, campo mais bibliográfico que disciplinar dedicado à investigação de questões intelectuais ${ }^{3}$. O aparecimento de três artigos, todos publicados na década de 1960 , pode ser considerado o início de uma produção e de um debate que acabou por constituir-se em uma inflexão no campo da história das idéias. Em 1962, John Pocock publica The History of Political Thought: a Methodological Enquiry (POCOCK, 1962). Em seguida, aparece The Identity of the History of Ideas, publicado em 1968 por John Dunn (DUNN, 1980). Por fim, Quentin Skinner, que seria o mais destacado membro do grupo, publica Meaning and Understanding in the History of Ideas, em 1969 (SKINNER, 1988). Desde então, proliferaram as discussões acerca das perspectivas analíticas, da escolha de fontes e mesmo da autonomia desse campo intelectual ${ }^{4}$. A importância daqueles trabalhos e a sincronia de suas preocupações e proposições podem ser melhor compreen-

\footnotetext{
$\overline{3}$ Um apanhado do movimento, em uma análise que transcende a contribuição dos historiadores de Cambridge, pode ser conferido em Silva (2009).

4 O debate pode ser acompanhado em um volume dedicado exclusivamente ao debate em torno das proposições e investigações de Quentin Skinner. Cf. Tully (1988). Sobre o contextualismo lingüístico e a contribuição de Quentin Skinner para a metodologia da história do pensamento político, cf. Silva (2010).
} 
didas nas palavras de um participante do debate: "O fulcro destes três trabalhos fundamentais, tomados em conjunto, era claro. Invocando as palavras de cada título, o que foi sendo afirmado era que a identidade da teoria política era histórica, que o método apropriado a ser empregado no seu estudo era o histórico, que o significado a ser derivado dos textos de teoria política, os quais sustentaram qualquer reivindicação para ser compreendidos, tinha que ser, ou demonstrado ter partido de um significado histórico identificável" (HAMPSHER-MONK, 2001, p. 159) ${ }^{5}$.

As idéias precisam de seu contexto, portanto, a compreensão de seus significados deve ser histórica. A concordância dos três autores parece acabar nesse ponto. Os limites, ou mesmo as fronteiras do contexto necessário para a adequada compreensão de um texto político; os limites impostos pelas linguagens políticas; ou, ainda, a validade dos textos clássicos, são temas de uma discussão que ainda não acabou ${ }^{6}$.

Uma das propostas do grupo de Cambridge é situar linguisticamente a expressão de idéias. Uma dificuldade inicial para a localização do significado de determinada expressão, reside, justamente, na problemática aproximação com o significado original de determinado texto. Um dilema seria a impossibilidade de compreender o significado que

5 Tradução livre do autor. Original: "The thrust of these three foundational works, taken together was clear. Invoking the words of each title, what was being asserted was that the identity of political theory was historical, that the appopriate method to be deployed in its study was a historical, that the meaning to be derived from political theory texts which vindicated any claim to have understood them had to be, or be shown to be departing from, a historically indetifiable meaning".

6 Sobre este aspecto, cf. Tuck (1992, p. 274-275). Mesmo um termo, ou nomenclatura, para esses trabalhos não é unívoco, como mostra a seguinte passagem: "Já utilizei duas expressões, 'história do pensamento político' e 'história do discurso político', que nitidamente não são idênticos. [...] No entanto, as mudanças por que tem passado esse ramo da historiografia nas duas últimas décadas podem ser caracterizados como um movimento de abandono da ênfase na história do pensamento (e de forma mais acentuada, 'das idéias') rumo a uma ênfase de algo bastante diferente - por isso a expressão 'história do discurso' embora não isenta de problemas nem irrepreensível - parece ser a melhor terminologia encontrada até o momento" (POCOCK, 2003, p. 24). Para desdobramentos contemporâneos do debate, bem como a relação da história do pensamento político com a teoria política, cf. Silva (2008). determinado autor pretendeu conferir ao seu escrito, sem considerar as expectativas do leitor contemporâneo acerca do que o autor do passado queria dizer. O leitor está definitivamente ligado ao seu próprio mundo intelectual (SKINNER, 1988).

Portanto, alcançar o significado de um texto é, necessariamente, acessar seu vocabulário na procura de significados referidos historicamente, evitando-se, assim, qualquer forma de anacronismo (idem). O equipamento mental do observador deve estar suficientemente informado e treinado para penetrar nos significados que estão necessariamente presos a um vocabulário datado, elaborado para dar conta de problemas e perplexidades específicas, como foi bem observado por Clifford Geertz, quando estava às voltas com a procura de um arsenal teórico adequado para compreender um mundo em pedaços: "A teoria política, que se apresenta como abordando questões universais permanentes a respeito do poder, da obrigação, da justiça e do governo em termos gerais e incondicionais, a verdade sobre as coisas, tais como no fundo sempre são em toda parte, necessariamente, é, na verdade e de maneira inevitável, uma resposta específica a circunstâncias imediatas. Por mais cosmopolita que possa ter a intenção de ser, ela é, como a religião, a literatura, a historiografia ou o direito, movida e animada pelas exigências do momento: um guia para perplexidades particulares, prementes, locais e ao alcance da mão" (GEERTZ, 2001b, p. 191).

A sugestão dos historiadores aqui considerados é, portanto, de que se deve investigar como determinadas respostas foram formuladas especificamente para responder a questionamentos característicos de determinado período. Assim, a leitura de um texto histórico deve ser feita tendose em mente que se está diante de um produto histórico, em que as intenções autorais (no caso específico de Skinner) constituem-se no guia mais importante para o apontamento de por que o texto assumiu sua forma particular.

Das diversas advertências metodológicas e epistemológicas feitas pelos partícipes da Escola de Cambridge, pode-se depreender que o contexto em que circulam as idéias é fundamental para a compreensão do próprio significado destas, conforme indica a passagem seguinte: "Uma 'linguagem' no nosso sentido específico é, então, não apenas uma maneira de falar prescrita, mas também tema de discussão prescrito para o discurso político. Neste ponto, podemos ver que, cada 
contexto lingüístico indica um contexto político, social ou histórico, no interior do qual a própria linguagem se situa. Contudo, neste mesmo ponto, somos obrigados a reconhecer que cada linguagem, em certa medida, seleciona e prescreve o contexto dentro do qual ela deverá ser reconhecida" (POCOCK, 2003, p. 36-37) ${ }^{7}$.

Tomadas em seu conjunto, as proposições dos historiadores de Cambridge convergem para um ponto: o contextualismo. E o uso de um contexto para a compreensão de um fenômeno social deve ser lido como vinculação à virada interpretativa, indicando a importância das reflexões sobre a linguagem ordinária na constituição das Ciências Sociais na segunda metade do século XX.

Mesmo sendo um fenômeno das Ciências Sociais, conforme o arrazoado imediatamente acima, os ataques dirigidos especificamente à cientificidade na análise política foram precisos e contundentes (TAYLOR, 1971; 1985b), até mesmo passíveis de críticas (SKINNER, 1973; GEERTZ, 2001a), e acabaram constituindo-se em um bom local de análise dos significados e intenções de atuantes protagonistas da virada interpretativa. As amarras entre as Ciências Sociais conectam seus praticantes e o interpretativismo é um elo relevante para desvelar essas conexões.

A virada interpretativa, cuja gênese pode ser localizada nas décadas de 1960 e 1970, radicalizou a perspectiva interpretativista presente no momento de fundação das Ciências Sociais. A argumentação dos interpretativistas da segunda metade do século XX defendia o caráter interpretativo do mundo social. Assim, a interpretação deixa de ser apenas uma forma de compreender a realidade, transformando-se também em um definidor ontológico do mundo e da ação humana no mundo. Conforme indicado por dois comentadores do fenômeno: "A virada interpretativa redirecionou a atenção para as variedades concretas do significado cultural, nas suas particularidades e complexa textura, mas sem cair nas armadilhas do historicismo ou do relativismo cultural em suas

7 Ou ainda, como exemplo substantivo, a insistência de Quentin Skinner em demonstrar a postura cambiante de Hobbes em relação às raízes humanistas de sua formação, especialmente notáveis na utilização (p. ex. Leviatã) ou não (p. ex. Do cidadão) de recursos da retórica para desenvolvimento de sua escrita. Cf. Skinner (1999). formas clássicas. Para as ciências humanas, ambos os objetos de investigação - a rede de linguagem, símbolo e instituições que constituem a significação - e as ferramentas pelas quais a investigação e conduzida compartilham inseparavelmente o mesmo contexto difuso que é o mundo humano"8 (RABINOW \& SULLIVAN, 1979, p. 4-5)

Uma descrição densa: por uma teoria interpretativa da cultura (GEERTZ, 1989), exemplifica o fenômeno. $\mathrm{O}$ ataque de Clifford Geertz é dirigido a uma perspectiva que encontra no "comportamentalismo skinneriano" seu desenvolvimento mais enfático. Ao expor seu conceito de cultura, o antropólogo indica precisamente seu ponto de partida. Acreditando - "como Max Weber" - que o homem é um animal amarrado a teias de significado que ele mesmo teceu, Geertz assume a cultura como sendo essas teias.

A análise da cultura seria, portanto, não uma ciência experimental à procura de leis, mas uma ciência interpretativa à procura de significados (idem, p. 15). O restante do ensaio, segundo o próprio autor, é uma explicação sobre essa afirmativa. Quando praticando etnografia, o antropólogo não estaria lidando apenas com um método, mas sim com um tipo de esforço intelectual que ele nomeia descrição densa, tomando a noção de Gilbert Ryle (ibidem).

A pesquisa etnográfica deveria constituir-se como um esforço por situar o analista no mundo estudado (idem, p. 23), acessando o contexto a partir do qual os acontecimentos sociais podem ser descritos de forma inteligível, "[...] isto é, descritos com densidade" (idem, p. 24). A descrição etnográfica teria, então, três características: "[...] ela é interpretativa; o que ela interpreta é o fluxo do discurso social e a interpretação envolvida consiste em tentar salvar o 'dito' em um tal discurso da sua possibilidade de extinguir-se e fixálo de formas pesquisáveis" (idem, p. 31). E ainda

\footnotetext{
8 Tradução livre do autor. Original: "The interpretive turn refocuses attention on the concrete varieties of cultural meaning, in their particularity and complex texture, but without falling into the traps of historicism or cultural relativism in their classical forms. For the human sciences both the objetc of investigation - the web of language, symbol, and institutions that constitutes signification and the tools by which investigation is carried out share inescapably the same pervasive context that is human world".
} 
deveria ser microscópica, na forma específica praticada por ele, assumindo que "as ações sociais são comentários a respeito de mais do que elas mesmas" (idem, p. 34). Além de comentários, as ações sociais realizam alguma coisa.

A Antropologia, portanto, (e tomo como uma idéia aplicável ao conjunto das Ciências Sociais) deve preocupar-se não com o ato em si, mas com que ocorre por meio da sua agência. Uma formulação próxima aos interesses de Skinner em relação às intenções autorais e, principalmente, de sua intenção declarada de escrever a história do pensamento político como uma história de ideologias (SKINNER, 2000).

\section{NATURALISMO EANTINATURALISMO NA CIÊNCIA POLÍTICA}

Os mais recentes esforços de revitalização do enfoque interpretativo na Ciência Política têm sua gênese na década de 1960, quando vários autores passaram a ressaltar a centralidade do estudo dos significados linguístico e hermenêutico dos fenômenos políticos. Dentre tais autores, destaca-se o filósofo Charles Taylor, cujos textos dos anos 1960 e 1970 representaram críticas contundentes contra o naturalismo subjacente ao mainstream da Ciência Política norte-americana da época, enfatizando que a posição de Charles Taylor deve ser compreendida como uma tentativa de fazer frente a uma ortodoxia que se tornara dominante no contexto acadêmico norte-americano de meados do século XX. Minha intenção aqui é apontar a crítica de Taylor ao comportamentalismo e ao naturalismo no âmbito da Ciência Política, bem como sumarizar as críticas que foram dirigidas aos seus argumentos.

Taylor é um autor que influenciou uma variedade de dimensões das ciências humanas. Seus estudos tematizaram assuntos diversos, colaborando para o desenvolvimento de várias disciplinas acadêmicas (ABBEY, 2004). Seus temas de interesse atravessam questões relativas à teoria moral, teorias da subjetividade, epistemologia e hermenêutica, entre outras (idem).

O estudioso canadense ainda deve ser lembrado como um importante partícipe do interpretive turn, sendo que suas reflexões ainda são relevantes para a compreensão das atuais perspectivas sobre o interpretativismo (CHOI, 2009). Um de seus comentadores caracteriza-o como um pensador hermeneuta justamente pela sua convicção de que os seres humanos são "criaturas que se autointerpretam" (self-interpreting creatures) (ABBEY, 2004, p. 3).

A idéia de que a interpretação é uma característica dos seres humanos é um desdobramento das críticas dirigidas ao naturalismo em seus primeiros escritos, nomeadamente em The Explanation of Behaviour, de 1964, originalmente sua dissertação de mestrado. Ao longo de sua trajetória de reflexão, o que era apenas uma crítica aos métodos de análise dirigiu-se paulatinamente para uma compreensão da natureza humana, interpretativa, que exigiria um compromisso que extrapola o método, configurando-se em uma postura epistemológica e ontologicamente comprometida com os elementos interpretativos desta natureza humana (CHOI, 2004). Mesmo com essa movimentação, é relevante notar que o próprio autor considera-se um obcecado em polemizar com a pretensão de cientistas sociais em pautar o estudo do homem nas ciências naturais (TAYLOR, 1985, p. 1). Inicialmente, as críticas de Taylor ao naturalismo concentram-se em apontar as limitações das prescrições comportamentalistas para a análise do comportamento de seres animados. A aplicação de critérios científicos para o estudo de seres animados resultaria em uma explicação pobre, uma vez que feitas em termos de leis e hipóteses causais. Segundo Taylor, a compreensão do comportamento de seres animados necessita de uma explicação teleológica, que consistiria na elucidação dos propósitos, intenções e objetivos envolvidos na ação (CHOI, 2009). Nas palavras do próprio autor: "[...] a prevalência da ordem não pode ser considerada em relação aos princípios que são somente eventuais ou 'acidentalmente' conectados com ele, por leis cuja operação somente eventualmente resulta nisso, mas deveria ser considerada em termos de ordem em si... os eventos produtivos de ordem em seres animados são para ser explicados não em termos de outra não-conectada condição antecedente, mas em termos de afinidades que elas produzem" (Taylor apud CHOI, 2009, p. 698) ${ }^{9}$.

\footnotetext{
9 Tradução livre do autor. Original: “[...] the prevalence of order cannot be accounted for on principles which are only contingent or 'accidentally' connected with it, by laws whose operation only contingently results in it, but must be accounted for in terms of the order itself ... the events productive of order in animate beings are to be explained not in terms of other unconnected antecedent conditions, but in terms of the very order which they produce".
} 
Na introdução de seu Philosophical Papers, o autor explicita o que teria sido o tema recorrente nos escritos ali reunidos: "Teorias deste tipo [...] parecem para mim ser terrivelmente implausíveis. Elas levam a uma ciência muito ruim (ou má): ou elas terminam em elaborações textuais óbvias, ou elas fracassam todas juntas em dirigir-se a questões interessantes, ou seus praticantes terminam desperdiçando seus talentos e ingenuidade na tentativa de mostrar que eles podem ao final das contas recapturar o entendimento da vida comum (ou ordinária) em suas manifestas linguagens reducionistas e explanatórias" (TAYLOR, 1985, p. 1) ${ }^{10}$.

O que merece ser ressaltado é a compreensão de bases diferentes para o compromisso de Taylor com o antinaturalismo (CHOI, 2009). Sua dissertação é uma crítica ao naturalismo em bases empíricas, ao passo que, em seus trabalhos subseqüentes, será sobre bases morais que o autor alicerçará seu antinaturalismo (idem). No primeiro momento, acompanhamos um argumento que se restringe a ressaltar as sérias limitações de um modelo de explicação calcado em um modelo científico para análise do mundo social; em segui$\mathrm{da}$, seu argumento dirige-se para um questionamento da pretensa separação entre fato e valor, adequadamente ilustrada pela sua afirmação da inexistência de diferenças entre bases morais e científicas (idem).

O movimento entre os dois momentos da crítica ao naturalismo feita por Charles Taylor pode ser periodizado. The Explanation of Behavior (TAYLOR, 1964), publicado originalmente em 1964, ainda representa seu compromisso com o antinaturalismo em bases empíricas. O artigo "Interpretation and the Sciences of Man", de 1971, está já ancorado no desdobramento de seu argumento, acima referido. Entre os dois momentos, um escrito que acredito poder ser tomado como "meio-caminho" entre as duas posições é "Neutrality in Political Science" (TAYLOR, 1985), originalmente publicado em 1967.

10 Tradução livre do autor. Original: "Theories of this kind [naturalistas] seem to me to be terribly implausible. They lead to very bad science: either they end up in wordy elaborations of the obvious, or they fail altogether to address the interesting questions, or their practitioners end up squandering their talents and ingenuity in the attempt do show that they can after all recapture the insights of ordinary life in their manifestly reductive explanatory languages".
Um ponto isolado por Taylor em "Neutrality in Political Science" é a pretensa necessidade de separação entre fato e valor, defendida por uma série de estudiosos da política. O início da problematização do autor aponta que a referida separação implicaria a superação da vinculação do estudo da política da sua origem filosófica, conforme o autor expressa nos seguintes termos: "De modo a avançar, a ciência deveria ser liberada do parti pris e ser valorativamente neutra. Assim, se a teoria normativa requer Ciência Política e não pode ser conduzida sem ela, o inverso não é o caso; Ciência Política pode e deve estar separada da disciplina mais velha [filosofia política]"11 (idem, p. 66; grifo no original).

A maturidade da ciência seria alcançada, portanto, por meio de uma análise do fenômeno político que prescinda da conexão entre fato e valor. A crítica de Taylor aponta para a impossibilidade dessa separação, tanto em termos da elaboração de teorias, quanto indicando o papel fundamental dos valores na significação e orientação do comportamento: "É por esta razão bastante óbvia que as necessidades humanas, desejos e propósitos têm uma influência importante sobre a forma como as pessoas agem, e que, portanto, é preciso ter uma noção da programação que não é extremamente imprecisa se alguém quiser estabelecer o quadro para qualquer ciência do comportamento humano, que não o de uma política de exceção. Uma concepção de necessidades humanas, assim, entra em uma determinada teoria política, e não pode ser considerada como algo estranho que nós adicionamos ao quadro para produzir um conjunto de juízos de valor"12 (idem, p. 75).

\footnotetext{
11 Tradução livre do autor. Original: "In order to progress science must be liberated from parti pris and be valueneutral. Thus if normative theory requires political science and cannot be carried on without it, the reverse is not the case; political science can and should be separated from the older discipline".

12 Tradução livre do autor. Original: "This is for the fairly obvious reason that human needs, wants, and purposes have an important bearing on the way people act, and that therefore one has to have a notion of the schedule which is not too wildly inaccurate if one is to establish the framework for any science of human behavior, that of politics not excepted. A conception of human needs thus enters into a given political theory, and cannot be considered something extraneous which we latter add to the framework to yield a set of value judgments".
} 
A inextricabilidade de valores, quando da formulação ou adoção de uma rede de suporte teórico, é algo que deve ser aceito pelos cientistas políticos. Mesmo que as considerações de Taylor sejam nomeadamente dirigidas a Seymour Lipset, ele toma o alvo como exemplo de uma postura corriqueira (ibidem). Seria, nomeadamente, o caso de teorias que utilizam a noção de função (idem, p. 76). Para que uma função seja cumprida, é necessária a existência de algum tipo de exigência. Quando o termo é utilizado em teoria social, as exigências geralmente estão conectadas às necessidades, vontades e propósitos humanos. A exigência, ou meta, relacionada à manutenção do sistema político, por exemplo, pode ser considerado essencial aos homens, ou capaz de assegurar ao homem uma série de benefícios que sistemas políticos podem trazer "[...] - estabilidade, segurança, paz, satisfação de determinados desejos e outros" (ibidem). Como a política é, em sua maior parte, feita a partir de atividades propositais dos homens, é plausível conceber as sociedades políticas em termos funcionais.

No entanto, enquanto caracterizamos sociedades em termos da sua realização, em termos diferentes e em diferentes degraus, de uma mesma série de funções, a dimensão crucial da variação, em termos dos propósitos explanatórios, é significativamente normativa. "Essas sociedades que satisfazem de maneira mais completa estas funções são melhores" (ibidem). Os termos e amplitude desse ponto da crítica de Taylor aos estilos naturalistas de teorização sobre a política são exemplarmente expressos na seguinte passagem: "Teorias deste tipo incluem não somente aqueles que fazem o uso explícito da 'função', mas também outras derivativas da teoria de sistemas e quadros que constroem a analogia com organismos. Isto poderia ser pensado para incluir, por exemplo, David Easton e Karl Deutsch. Para os requisitos pelos quais iremos julgar o funcionamento de diferentes sistemas políticos estão explícitos na teoria" (idem, p. 77) ${ }^{13}$.

13 Tradução livre do autor. Original: "Theories of this kind include not only those which make explicit use of 'function', but also other derivatives of systems theory and frameworks which build on the analogy with organisms. This might be thought to include, for instance, David Easton and Karl Deutsch. For the requirements by which we will judge the performance of different political systems are explicit in the theory". O livro considerado no trecho imediatamente anterior ao citado é Politics of the Developing
Os termos utilizados por Charles Taylor em sua crítica aos estilos empiristas, naturalistas ou comportamentalistas de teorização sobre a política são escrutinados por Quentin Skinner. Segundo Skinner, dois pontos podem ser tomados como referentes ao conjunto de críticas dirigidas à pretensa neutralidade da Ciência Política. Primeiro, que existem implicações normativas em análise da política que são apresentadas como neutras; em seguida, que os cientistas políticos dariam suporte aos sistemas políticos vigentes, e seus trabalhos teriam, portanto, um forte elemento conservador (SKINNER, 1973, p. 287-288). A essência do ataque seria, neste sentido, que os teóricos empiristas teriam feito um movimento "falso e ideológico", quando da elaboração de suas análises alegadamente neutras (idem, p. 288). Skinner sugere, no entanto, que essas críticas, na maior parte das vezes, ignoram, ao invés de refutar, as alegações dos teóricos empiristas (ibidem).

De um lado, Skinner afirma que as elaborações criticadas são tomadas em uma formulação geral e ideal que não seria aceita de maneira automática pelo conjunto de teóricos criticados. Além disso, versões mais sofisticadas da teoria criticada não são seriamente abaladas pelas críticas, como é o caso da produção de Robert Dahl, que será o alvo preciso das considerações seguintes de Skinner (idem, p. 289). O resultado do seu argumento não deixa dúvidas sobre suas reservas em relação às críticas dirigidas aos teóricos da democracia, que não teriam rebatido declarações destes teóricos em termos adequados, tendo feito um mesmo movimento ideológico tal qual o por eles criticado (idem, p. 297).

Se as primeiras críticas de Taylor foram dirigidas ao comportamentalismo como posição "supradisciplinar"14, em "Interpretation and the Sciences of Man", ao dedicar-se a análises naturalistas no âmbito estrito da Ciência Política, Taylor

Areas (ALMOND \& COLEMAN, 1960), publicado em 1960 por Gabriel Almond. Em nota, Taylor nomeia os livros criticados na citação acima: A Framework for Political Analysis (EASTON, 1965a) e A Systems Analysis of Political Life (EASTON, 1965b), ambos publicados em 1965, e The Nerves of Government, publicado em 1963 por Karl Deutsch.

14 Vale lembrar que Clifford Geertz inicia sua defesa particular da análise interpretativa atacando essa mesma postura comportamentalista. Cf. Geertz (1973). 
indica precisamente em que se origina a postura considerada: "Na política, também, o objetivo de uma ciência verificável levou à concentração em características que podem supostamente ser identificadas na abstração da nossa compreensão ou não compreensão do significado experiencial. Estes - vamos chamá-los de identificações de dados brutos - são o que supostamente permitem-nos sair do círculo hermenêutico e encontrar nossa ciência firmemente plantada em um processo de verificação que satisfaça os requisitos da tradição empirista" (TAYLOR, 1985a, p. 28) ${ }^{15}$.

A tradição empirista, que remonta aos escritos de autores ingleses do século XVII, imiscuiu-se na mentalidade moderna, arrogando-se a única capaz de propor uma apreensão adequada da realidade. Não só do mundo físico-natural, ressaltese, mas também do mundo social e da ação dos indivíduos neste mundo. Partindo de pressupostos equivocados (por exemplo, a dualidade cartesiana entre corpo e mente), a tradição empirista tornou dominante uma análise empobrecida da realidade. Não só empobrecida pela capacidade reduzida de dizer coisas adequadas sobre o mundo social, mas, além disso, comumente geradora de visões distorcidas da realidade.

As considerações de Clifford Geertz sobre os escritos de Taylor iniciam-se aceitando que a grande meta de Taylor é polemizar com uma única idéia: a ambição de pautar o estudo do homem nas ciências naturais (GEERTZ, 2001b, p. 131). Deve ser notado que Geertz possui profunda afinidade com a meta de Taylor, o que não o impede de apontar reservas em relação às formulações de seu colega. As reservas são de duas ordens. Primeiro, que a idéia com a qual a perspectiva interpretativista é contrastada aparece de forma esquemática. A "ciência natural" é tomada como um bloco, em direção ao qual são lançadas críticas, constituindo-se muito mais em um estereóti-

\footnotetext{
15 Tradução livre do autor. Original: "In politics, too, the goal of a verifiable science has led to the concentration on features which can supposedly be identified in abstraction from our understanding or not understanding experiential meaning. These - let us call them brute data identifications - are what supposedly enable us to break out from the hermeneutical circle and found our science four square on a verification procedure which meets the requirements of the empiricist tradition".
}

po do que em uma instituição viva e multifacetada (idem, p. 132). As referências a essas ciências naturais, apesar de numerosas na produção de Taylor, são marcadas por duas características deploradas por Geertz. Em primeiro lugar, raramente elas são circunstanciadas, descrevendo apenas de forma passageira exemplos reais de trabalhos em suas disciplinas; e todas praticamente dizem respeito às etapas iniciais da revolução científica (ibidem).

$\mathrm{O}$ abismo que se abre entre duas tradições de pensamento (seriam mesmo duas?) é obstrutivo ao desenvolvimento de ambas. Taylor teria desconsiderado formulações recentes no âmbito das ciências naturais, que não ficariam confortáveis com a maneira utilizada pelo autor para caracterizá-las (idem, p. 137-140). Além disso, a resistência de Taylor à intromissão do modelo natural nas ciências humanas aceita a existência de tal modelo, tomado como unitário, bem definido e historicamente imóvel (idem, p. 142). A posição de Geertz fica explícita na seguinte passagem: “Combater a 'naturalização' das ciências humanas é uma iniciativa necessária, para a qual Taylor contribuiu de maneira vigorosa; e devemos ser-lhe gratos pelo destemor de seus esforços nesse aspecto, e por sua precisão. Tomado, ele mesmo, por algumas fórmulas empoeiradas, Taylor, para prejuízo de todos nós, não contribuiu da mesma forma para a iniciativa não menos necessária de religar as ciências naturais a suas raízes humanas e, desse modo, combater a naturalização delas. É uma grande lástima que alguns dos fenômenos de maior peso na cultura contemporânea estejam ocorrendo fora da atenção de um dos mais profundos estudiosos dessa cultura" (idem, p. 142; grifo no original).

\section{CONCLUSÕES}

O debate sobre métodos e posturas interpretativistas constitui-se em um vigoroso caminho trilhado pelas Ciências Sociais, e sua compreensão poderá não somente iluminar as análises do mundo social, como também manter uma preocupação de segunda ordem, qual seja, uma atitude reflexiva em relação aos pressupostos metodológicos e epistemológicos que presidem a atividade dos cientistas sociais.

Minhas futuras preocupações serão organizadas partindo de duas questões no amplo debate interpretativista. Primeiro, a idéia de separação entre valores e análise. Qual o papel que os valores e 
crenças dos analistas desempenham na elaboração de suas análises e na condução de suas pesquisas? Relacionado a este ponto, emerge a questão da isenção ao proceder-se a análise do mundo social. A cisão entre valores e fatos (defendida pelas abordagens naturalistas) pode ser plenamente alcançada? Quais os limites e possibilidades de isenção, levando em conta a condição interpretativa dos homens e de sua ação no mundo?

Quais os critérios para uma interpretação adequada? Como alcançar uma compreensão adequada dos fenômenos sociais? Esta tarefa deve concentrar-se na elaboração de uma justificativa para a proposição de uma Ciência Política de cunho interpretativo e informada contextualmente. Tornando possível advogar um resultado válido para assertivas sobre o mundo, mesmo que não baseadas em um procedimento científico. Tornar-seia, assim, defensável que, para uma efetiva compreensão do significado do mundo social e da circulação humana no mundo, é possível utilizar-se "medidores" outros que não aqueles baseados em um método, mas sim aqueles que se aproximam de uma heurística (BEVIR, 2008). Uma objetividade construída sob critérios de comparação entre narrativas concorrentes (ibidem). Essas perguntas, e as respostas provisórias que podem emergir do presente ensaio, devem servir como fio condutor para novas análises.

Por último, noto que, para o sucesso dessa empreitada, é fundamental uma reflexão sobre a natureza do entendimento humano sobre o mundo. Aliás, é esse o caminho percorrido por Charles Taylor nos trabalhos seguintes ao reposicionamento das bases de sua crítica ao naturalismo, levando o autor à consideração dos elementos constitutivos da identidade moderna. O que somos em grande medida está ligado ao que imaginamos ser. Portanto, o estudo sobre o mundo dos homens deve levar em conta aquilo que conforma nossa identidade. Uma conformação resultante de interpretações, que serão investigadas por meio de outras interpretações.

Tiago Losso (tiagolosso@gmail.com) é Doutor em Ciências Sociais pela Universidade Estadual de Campinas (Unicamp) e Professor de Sociologia e Ciência Política na Universidade Federal de Santa Catarina (UFSC).

\section{REFERÊNCIAS BIBLIOGRÁFICAS}

ABBEY, R. (ed.). 2004. Charles Taylor. New York: Cambridge University.

ALMOND, G. \& COLEMAN, J. S. (eds.). The Politics of the Developing Areas. Princeton: Princeton University.

BEVIR, M. 2008. A lógica da história das idéias. São Paulo: VSC.

2000. The Role of Contexts in Understanding and Explanation. Human Studies, New York, n. 23, p. 395-411, Oct.

BEVIR, M. \& KEDAR, A. 2008. Concept Formation in Political Science: an AntiNaturalist Critique of Qualitative Methodology. Perspectives on Politics, Cambridge (UK), v. 6, n. 3, Sept.

CHOI, N. 2009. Defending Anti-Naturalism After the Interpretive Turn: Charles Taylor and the Human Sciences. History of Political Thought, Exeter, v. XXX, n. 4, p. 693-718.
DUNN, J. 1980. The Identity of the History of Ideas. In:_. Political Obligation in its Historical Contexts: Essays in Political Theory. Cambridge (UK): Cambridge University.

EASTON, D. 1965a. A Framework for Political Analysis. Englewood Cliffs: Prentice-Hall.

.1965b. A Systems Analisys of Political Life. New York: Willey.

FERES JR., J. 2000. Aprendendo com os erros dos outros: o que a história da Ciência Política americana tem para nos contar. Revista de Sociologia e Política, Curitiba, n. 15, p. 97-110, nov. Disponível em: http://www.scielo.br/pdf/ rsocp/n15/a07n15.pdf. Acesso em: 30.abr.2011.

GEERTZ, C. 1989. Uma descrição densa: por uma teoria interpretativa da cultura. In: interpretação das culturas. Rio de Janeiro: LTC. 
2001a. O estranho estranhamento: Charles

Taylor e as ciências naturais. In: . Nova luz sobre a Antropologia. Rio de Janeiro: J. Zahar.

2001b. O mundo em pedaços: Cultura e política no fim do século. In: . Nova luz sobre a Antropologia. Rio de Janeiro: J. Zahar.

2001c. Prefácio. In: . Nova luz sobre a Antropologia. Rio de Janeiro: J. Zahar.

GIBBONS, M. T. 2006. Hermeneutics, Political Inquiry, and Practical Reason: An Evolving Challenge to Political Science. American Political Science Review, Los Angeles, v. 100, n. 4, p. 563-171, Nov. Disponível em: http:// w w w a p s a e t.org/i m g tes t/ APSRNov06Gibbons.pdf. Acesso em: 30.abr.2011.

HAMPSHER-MONK, I. 2001. The History of Political Thought and the Political History of Thought. In: CASTIGLIONE, D. \& HAMPSHER-MONK, I. The History of Political Thought in National Context. Cambridge (UK): Cambridge University.

POCOCK, J. G. A. 1962. The History of Political Though: a Methodological Enquiry. In: LASLETT, P. \& RUNCIMAN, W. G. (eds.). Philosophy, Politics and Society. Oxford: Blackwell.

2003. Linguagens do pensamento político. São Paulo: USP.

RABINOW, P. \& SULLIVAN, W. M. (eds.). 1979. Interpretive Social Science: a Reader. Berkeley: University of California.

SILVA, R. 2008. Liberdade e lei no neorepublicanismo de Skinner e Pettit. Lua Nova, São Paulo, n. 74, p. 151-194. Disponível em: http://www.scielo.br/pdf/ln/n74/07.pdf. Acesso em: 30.abr.2011.

2009. História intelectual e teoria política. Revista de Sociologia Politica, Curitiba, v. 17, n. 34, p. 301-318. Disponível em: http:/ /www.scielo.br/pdf/rsocp/v17n34/ a20v17n34.pdf. Acesso em: 30.abr.2011.

2010. O contextualismo linguístico na história do pensamento político: Quentin Skinner e o debate metodológico contemporâneo. Dados, Rio de Janeiro, v. 53, n. 2, p. 299-335. Disponível em: http://www.scielo.br/ pdf/dados/v53n2/02.pdf. Acesso em: 30.abr. 2011.

SKINNER, Q. 1973. The Empirical Theorists of Democracy and Their Critics: A Plague on Both Their Houses. Political Theory, Thousand Oaks, v. 1, n. 3, p. 287-306, Aug.

1988. Meaning and Understanding in the history of ideas. In: TULLY, J. (ed.). Meaning and Context: Quentin Skinner and His Critics. Cambridge (UK): Polity.

1999. Razão e retórica na filosofia de Hobbes. São Paulo: Unesp.

2000. Quentin Skinner (Entrevista a Maria Lúcia Garcia Pallares-Burke). In: PALLARES-BURKE, M. L. G. As muitas faces da história. Nove entrevistas. São Paulo: Unesp.

TAYLOR, C. 1964. The Explanation of Behavior. London: Routledge.

1985a. Interpretation and the Science of Man. In:_. Philosophy and the Human Sciences. Philosophical Papers 2. Cambridge (UK): Cambridge University.

1985b. Neutrality in Political Science. In: . Philosophy and the Human Sciences. Philosophical Papers 2. Cambridge (UK): Cambridge University.

TUCK, R. 1992. História do pensamento político. In: BURKE, P. (org.). A escrita da história: novas perspectivas. São Paulo: Unesp.

TULLY, J. 1988. Meaning and Context. Quentin Skinner and His Critics. Cambridge (UK): Polity.

\section{OUTRAFONTE}

COMISSÃO GULBENKIAN. 1996. Para abrir as Ciências Sociais. São Paulo: Cortez. 